\title{
Predictors of relaparotomy for persisting intra abdominal infec- tion in secondary peritonitis
}

\author{
Abel Shiferaw Tesfaye ${ }^{a,}{ }^{,}$, Henock T/Selase ${ }^{b}$ \\ ${ }^{a}$ Department of Surgery, Addis Ababa University, college of health science, school of Medicine, Yeka Sub city, Addis Ababa, Ethiopia. \\ ${ }^{b}$ Department of Surgery, Addis Ababa University, college of health science, school of Medicine, Bole Sub city, Addis Ababa, Ethiopia.
}

\begin{abstract}
Background: Peritonitis is one of the commonest causes of acute abdomen in Ethiopia. One of the causes of high morbidity and mortality is persistent intraabdominal infection. The two essential approaches for managing post-op collection are laparotomy on-demand and planned Relaparotomy. Despite multiple studies, both have comparative mortality. This study aimed to identify clinical variables that are predictive of persistent intraabdominal infection.

Methods: A retrospective study was conducted on patients who were operated on from Sept 2018 to April 2020 at two affiliated referral hospitals of AAU, college of Medicine; Yekatit 12 hospital Medical College and Minilik II referral Hospital. All of the patients were cases of secondary peritonitis. Clinical progress of the patients from admission to discharge/death was documented. Multiple preoperative and intraoperative variables were analyzed to develop the predictive clinical model.

Results: Out of 172 laparotomy cases for secondary peritonitis, 40 (23.3\%) required relaparotomy for postop collection. From Patients who developed postop collection, $45 \%$ of them were diagnosed after pus/Gi content leaked through the surgical wound. The mortality rate of patients who develop postop collection and undergone relaparotomy was $27.5 \%$ and $4.5 \%$ for those without postop collection. Logistic regression identified 4 variables as having significant predictive value: Duration of illness more than 5 days, Systolic BP $</=90 \mathrm{mmHg}$, Amount of peritoneal fluid $>1000 \mathrm{ml}$, and small bowel as a source of contamination. Overall prediction successes of the above model is $88.4 \%$ (sensitivity $53.3 \%$, specificity $96.8 \%$ ).

Conclusion: Management of persistent intra-abdominal infection is challenging. We have identified 4 clinical variables that predict persistent intraabdominal infection requiring relaparotomy. These sets of variables can be a milestone for future validation study before being inserted in today to day clinical practice.

Keywords: Relaparotomy; Predictors; Laparotomy; Secondary peritonitis; Intra-abdominal infection
\end{abstract}

\section{INTRODUCTION}

Peritonitis is one of the commonest causes of acute abdomen with a high mortality rate ranging from 10 $60 \%$ depending on the study in western countries ${ }^{[1]}$

\footnotetext{
* Corresponding author: Abel Shiferaw Tesfaye

Mailing address: Department of Surgery, Addis Ababa University, college of health science, school of Medicine, Yeka Sub city, Addis Ababa, Ethiopia.

E-mail: abelshiferaw3417@gmail.com

Received: 24 June 2021 / Accepted: 19 July 2021
}

and it is one of the commonest causes of acute abdomen in Ethiopia ${ }^{[2-6]}$. Secondary Peritonitis accounts for approximately $90 \%$ of all peritonitis cases in western countries ${ }^{[7,8]}$.

Irrespective of the cause, successful management of peritonitis includes early administration of antibiotics, timely and effective surgical intervention, and supportive care to maintain organ function and limit the development of multiple organ failure ${ }^{[9-11]}$. One of the main causes of death is failure to control the initial infection and persistence of bacterial peritonitis. To minimize these risks, the concept of "relaparotomy" was introduced. 
Incidence of relaparotomy ranges from $0.5-15 \%$ in various reported studies ${ }^{[12-14]}$. The studies suggest early intervention reduces mortality by decreasing multiorgan failure ${ }^{[15]}$.

Despite the development of antibiotics and significant improvement in intensive care support, mortality after relaparotomy ranges from 24 to $71 \%{ }^{[12,13,16]}$.

The two essential approaches for managing post-op collection are RL on-demand ("wait and see" approach) and planned RL ${ }^{[17]}$. Planned relaparotomy detects persistent infection early, before the occurrence of MODS; while high negative relaparotomy is the drawback. In On-demand relaparotomy, exploration is limited to patients who developed signs and symptoms of persistent intraabdominal infection. The disadvantage of this strategy is the late detection of the postop collection after SIRS develops.

Both strategies have advantages and disadvantages and are still used side-by-side in clinical practice despite growing support for on-demand strategy. The studies conducted in the past few years do not seem to suggest that either approach confers a superior advantage in terms of mortality ${ }^{[18-21]}$.

A meta-analysis conducted by Lamme et al. in 2002 comparing planned vs on-demand relaparotomy strategies showed in-hospital mortality was 0.70 (95\% confidence interval 0.27 to 1.80 ) in favor of the ondemand strategy, but it was not statistically significant [18].

Rakic et al analyzing the outcomes of 65 patients with severe peritonitis and concluded although planned laparotomy seemed to have a lower mortality rate, there was no significant difference after adjustments ${ }^{[19]}$.

In 2004 Lamme et al conducted a retrospective study on 278 patients with secondary peritonitis and found a significantly lower hospital mortality rate for ondemand laparotomy (21.8\% vs. $36 \% ; P=0.016$ ) and a better two-year survival rate $(65.8 \%$ vs. $55.5 \%$; $P=$ $0.031)^{20]}$.

The only Randomized clinical trial was conducted by van Ruller et al. in 7 teaching hospitals in the Netherlands including a total of 232 patients ${ }^{[21]}$. The study showed death and major morbidity, were similar in the two groups at 12 months (mortality 29\% on-demand and $36 \%$ planned; $P=0.23$; morbidity $40 \%$ on-demand and $44 \%$ planned; $P=0.58$ ). However, there were significant differences in the secondary outcomes, with the on-demand group having significantly shorter ICU stays (7 vs. 11 days), fewer hospital days (27 vs 35), and lower cost (23\% less).
As already mentioned both strategies have comparable mortality, but there is still ongoing researches being done to find out some specifications that help to address specific strategies, specifically planned relaparotomy. But in the end, all concluded rather than specifying a single strategy, they prefer to give extra care and attention to patients with specific factors to have a low clinical threshold for early relaparotomy in these patients.

The objective of this study was to identify preoperative and intraoperative clinical factors that may predict ongoing abdominal infection and the need for relaparotomy to construct a clinical model to assist clinicians in predicting the need for relaparotomy in patients with persisting intraabdominal infection in secondary peritonitis.

There are very little data on this specific problem from the developing world, where the spectrum of disease is markedly different from that in the developed world [21-27].

\section{METHODOLOGY}

\section{Study design}

A retrospective cross-sectional quantitative design was used to conduct the study, with an analytical approach adopted to determine the predictors of relaparotomy for persistent intraabdominal infection.

\section{Study Setting}

This study was conducted in the two affiliated referral hospitals of AAU, college of Medicine, Addis Ababa. These hospitals are Yekatit 12 teaching hospital and Minilik II referral Hospital. The surgical departments of these hospitals are the training sites for surgical residents of the postgraduate program of the College of Health Science, AAU.

\section{Study population}

A total of 172 consecutive patients with secondary peritonitis who had undergone laparotomy from Sept 1, 2019, to April 08, 2020, were included in this study.

\section{Inclusion criteria}

All patients admitted and operated for secondary peritonitis in the department in the two affiliated hospitals of AAU, college of Medicine within this time frame were included.

\section{Exclusion criteria}

Patient with initial laparotomy done in other hospitals; Patients with negative laparotomy; 
Patients with acute pancreatitis;

Patients with mesenteric Ischemia;

Patient with already planned relaparotomy;

Patient with TB peritonitis;

A patient who has undergone a relaparotomy for other causes (bleeding, wound dehiscence...);

Patients with peritonitis following trauma.

\section{Source of data}

Patients' medical chart was main source data. Basic demographic data (age, sex, place of referral) were collected. The clinical symptoms, findings on physical examination, post-resuscitation vital signs, and laboratory results were recorded. Intraoperative details were extracted from the operation note.

Additional information was extracted from the emergency room triage paper, operation logbook, and HMIS. Data were collected using a structured questionnaire and it was collected by the primary investigator.

\section{Statistical analysis}

The patients were divided into two groups, the relaparotomy, and the non-relaparotomy group. More than 20 preop and intraop factors were evaluated concerning their significance in predicting the need for relaparotomy for postop collection.

Student's t-test for continuous variables and the chisquared test for nominal variables were run to identify any significant differences between the two groups. Logistic multiple regression was then performed using all factors found significant on this univariate analysis. Those variables with a $P$-value less than 0.05 were considered significant and were inserted in the predictive model.

All data analysis was performed using IBM SPSS Statistics (version 23).

\section{Ethical Consideration}

Ethical clearance for the study was obtained from Addis Ababa University, College of Health Science Institutional Review Board. Data collection was undertaken after permission is obtained from the administration. The identities of the study participants will not be disclosed. The collected questionnaires were not transferred to a third party.

\section{Operational definitions}

1. Relaparotomy: - Abdominal operations that have to be redone within 60 days in association with the initial surgery

Positive findings - turbid or purulent intra-abdominal fluid with/out Gi content.
Negative findings - minimal amounts of serous fluid with no other new findings in the abdomen.

2. Referred from any rural center: - being referred from outside of Addis Ababa.

3. Antibiotic intake before Surgery: - any antibiotic taken(PO or IV) for more than $24 \mathrm{hr}$ with an intention of treatment, before surgery.

4. Localized Peritonitis: - peritoneal inflammation localized to a specific quadrant.

5. Generalized peritonitis:- inflammation involving all or most of the peritoneal surface.

6. Previous abdominal surgery: - any open abdominal surgery that breaches the peritoneum.

\section{RESULTS}

During the study period, 172 eligible cases were admitted and operated on for secondary peritonitis in the two hospitals. 102 patients were operated on at Minilik II hospital and 70 patients were operated on at Yekatit hospital.

Out of 172 patients, $70.9 \%$ of the patients were males and $29.1 \%$ were females. The Median age group of patients was $25 \mathrm{yrs}$, with $53.5 \%$ of them lie between 15 yrs and 34 yrs. $82 \%$ of patients were referred from Addis Ababa, while 18\% were from outside of Addis Ababa (Table 1). The commonest comorbid disease that was found was hypertension (4.1\%), followed by HIV (2.3\%) and DM (1.7\%).

The median length of time from the onset of symptoms to seeking medical care was 3 days. In our study, 93\% of our patients fall into ASA 1 and 2 scores. In physical examination, the median systolic BP was 110 and diastolic BP was 70. The median pulse rate was 110 . Information about preoperative factors is also summarized in (Table 2).

Table 1. Patients and Stone Characteristics.

\begin{tabular}{llll}
\hline & $\begin{array}{l}\text { Re- } \\
\text { laparotomy }\end{array}$ & $\begin{array}{l}\text { Non- } \\
\text { relaparotomy }\end{array}$ & $\begin{array}{l}\boldsymbol{P} \text { - } \\
\text { value }\end{array}$ \\
\hline $\begin{array}{lll}\text { Gender (\%) } \\
\text { Male }\end{array}$ & $60 \%$ & $74.2 \%$ & 0.082 \\
Female & $40 \%$ & $25.8 \%$ & \\
Age(yrs) Median & 26 & 25 & 0.062 \\
Place of Referral & & & 0.007 \\
From Addis Ababa & $67.5 \%$ & $86.4 \%$ & \\
From Rural Center & $32.5 \%$ & $13.6 \%$ & \\
Comorbidities & & & 0.734 \\
Hypertension & $5 \%$ & $3.8 \%$ & 0.073 \\
Diabetes & $5 \%$ & $0.8 \%$ & 0.933 \\
HIV & $2.5 \%$ & $2.3 \%$ &
\end{tabular}


Of all cases of peritonitis, 72.7 cases had generalized peritonitis, while $27.3 \%$ had localized peritonitis. To access the peritoneum, a limited incision was used in $24.4 \%$ of patients, while full laparotomy was used in $75.6 \%$ of patients. While assessing the intraop factors, the most common cause of secondary peritonitis was complicated appendicitis (52.9\%), followed by perforated PUD (33.1\%), small bowel pathology ( $4.7 \%)$, and colonic pathology (4.7\%). During exploration, pus was found $68.8 \%$ of the time, while GI content mixed with pus was found $28.5 \%$ of the time. The mean amount of peritoneal fluid was $673.4 \mathrm{ml}$, more than $1000 \mathrm{ml}$ of peritoneal fluid was found in $22.5 \%$ of patients.

During exploration, ischemic bowel and underlying malignancy were found in $4.7 \%$ and $1.7 \%$ of patients respectively. A drainage tube was left in $64 \%$ of patients after exploration. Intraoperatively, inotropes and/or vasopressors were required in $2.3 \%$ of patients. Intraop bowel injury was observed in $3.5 \%$ of cases. In $18.6 \%$ of cases, the diagnosis was changed after exploration and intraop finding. $4.1 \%$ of patients had previous abdominal surgery. The median duration of surgery was $110 \mathrm{~min}$. All intraoperative data are shown in (Table 3).

Out of 172 laparotomy cases for secondary peritonitis, $40(23.3 \%)$ required relaparotomy for postop collection. From Patients who developed postop collection, $45 \%$ of them were diagnosed after pus/Gi content leaked through the surgical wound, while the rest were diagnosed with clinical signs augmented with imag-

Table 2. Preoperative Data for each Group.

\begin{tabular}{llll}
\hline & $\begin{array}{l}\text { Re- } \\
\text { laparotomy }\end{array}$ & $\begin{array}{l}\text { Non- } \\
\text { relaparotomy }\end{array}$ & $\begin{array}{l}\boldsymbol{P} \text { value } \\
\text { value }\end{array}$ \\
\hline $\begin{array}{l}\text { Duration of illness } \\
\text { (hrs) Mean }\end{array}$ & 65.7 & 107.8 & $<0.001$ \\
$\begin{array}{l}\text { Antibiotic treatment } \\
\text { before Surgery }\end{array}$ & $22.5 \%$ & $16.7 \%$ & \\
$\begin{array}{l}\text { Preop Systolic BP, } \\
\text { Mean }\end{array}$ & 104.4 & 112.2 & 0.005 \\
$\begin{array}{l}\text { Preop Diastolic BP, } \\
\text { Mean }\end{array}$ & 66.5 & 68.6 & 0.277 \\
$\begin{array}{l}\text { Preop Heart rate, } \\
\text { Mean }\end{array}$ & 114.2 & 109.3 & 0.092 \\
$\begin{array}{l}\text { Investigation } \\
\text { WBC Count, }\end{array}$ & 13474.25 & 13582.65 & 0.922 \\
$\begin{array}{l}\text { Mean } \\
\text { Hemoglobin Level, } \\
\text { Mean }\end{array}$ & 14.13 & 14.9 & 0.101 \\
$\begin{array}{l}\text { Platelet Count, } \\
\text { Mean }\end{array}$ & 299700 & 291523 & 0.742 \\
Previous abdominal & $5 \%$ & $3.8 \%$ & 0.734 \\
\hline
\end{tabular}

ing. Of the 40 patients who developed postop collection, 33(82.5\%) of them only require 1 relaparotomy, $6(15 \%)$ of them underdone 2 relaparotomy, and $1(2.5 \%)$ was reoperated 3 times.

The median duration between laparotomy for peritonitis and first relaparotomy for the postop collection

Table 3. Intraoperative data for each Group.

\begin{tabular}{|c|c|c|c|}
\hline & $\begin{array}{l}\text { Re- } \\
\text { laparotomy }\end{array}$ & $\begin{array}{l}\text { Non- } \\
\text { relaparotomy }\end{array}$ & $\begin{array}{l}P \text { - } \\
\text { value }\end{array}$ \\
\hline $\begin{array}{l}\text { Presence Of Ischemic } \\
\text { bowel }\end{array}$ & $10 \%$ & $3 \%$ & 0.067 \\
\hline $\begin{array}{l}\text { Use of Inotropic } \\
\text { /Vasopressive Agents }\end{array}$ & $0 \%$ & $3 \%$ & 0.265 \\
\hline $\begin{array}{l}\text { Presence of } \\
\text { underlying } \\
\text { malignancy }\end{array}$ & $5 \%$ & $0.8 \%$ & 0.073 \\
\hline Extent of Peritonitis & & & 0.977 \\
\hline $\begin{array}{l}\text { Generalized } \\
\text { Peritonitis }\end{array}$ & $72.5 \%$ & $72.7 \%$ & \\
\hline Localized Peritonitis & $27.5 \%$ & $27.3 \%$ & \\
\hline $\begin{array}{l}\text { Source of in- } \\
\text { traabdominal } \\
\text { Contamination }\end{array}$ & & & $<0.001$ \\
\hline Appendix & $44.7 \%$ & $56.1 \%$ & \\
\hline $\begin{array}{l}\text { Stomach and } \\
\text { Duodenum }\end{array}$ & $26.3 \%$ & $35.6 \%$ & \\
\hline Jejunum and Ileum & $15.8 \%$ & $1.5 \%$ & \\
\hline Colon & $13.2 \%$ & $2.3 \%$ & \\
\hline Tubo-ovarian & $0 \%$ & $2.3 \%$ & \\
\hline Gall Bladder & $0 \%$ & $2.3 \%$ & \\
\hline $\begin{array}{l}\text { Type of peritoneal } \\
\text { fluid }\end{array}$ & & & $<0.001$ \\
\hline Turbid & $12.5 \%$ & $0 \%$ & \\
\hline Pus & $57.5 \%$ & $72 \%$ & \\
\hline GI \pm Pus & $30 \%$ & $28 \%$ & \\
\hline $\begin{array}{l}\text { Amount of peritoneal } \\
\text { fluid }\end{array}$ & & & $<0.001$ \\
\hline$<1000 \mathrm{ml}$ & $51.5 \%$ & $84.3 \%$ & \\
\hline$\geq 1000 \mathrm{ml}$ & $48.5 \%$ & $15.7 \%$ & \\
\hline $\begin{array}{l}\text { Surgical access } \\
\text { to peritoneum }\end{array}$ & & & 0.747 \\
\hline Laparotomy & $22.5 \%$ & $25 \%$ & \\
\hline Limited Incision & $77.5 \%$ & $75 \%$ & \\
\hline $\begin{array}{l}\text { Drainage tube } \\
\text { placement }\end{array}$ & $52.5 \%$ & $67.4 \%$ & 0.085 \\
\hline $\begin{array}{l}\text { Intra op change } \\
\text { in diagnosis }\end{array}$ & $35 \%$ & $13.6 \%$ & 0.002 \\
\hline Intraop bowel injury & $5 \%$ & $3 \%$ & 0.552 \\
\hline $\begin{array}{l}\text { Duration of } \\
\text { Surgery (min) }\end{array}$ & 145.6 & 109.8 & $<0.001$ \\
\hline $\begin{array}{l}\text { Admitted to ICU } \\
\text { in immediate Postop }\end{array}$ & $7.5 \%$ & $4.5 \%$ & 0.462 \\
\hline
\end{tabular}


was 7.5 days, with $30 \%$ of the cases, is beyond 10 days. The mean duration of hospital stay for all peritonitis cases with no postop collection was 7 days, while those with postop collection requiring relaparotomy were 21.9 days. In Our study, the mortality rate of patients who develop postop collection and undergone relaparotomy was $27.5 \%$ and $4.5 \%$ for those without postop collection.

Based on the differences between the relaparotomy and nonrelaparotomy groups, several parameters were found to be significant on Chi-square and student- $t$ correlation tests. These variables were included in a logistic regression model to predict the need for relaparotomy. Duration of illness more than 5 days, Systolic $\mathrm{BP}</=90 \mathrm{mmHg}$, Amount of peritoneal fluid $>1000$ $\mathrm{ml}$, and small bowel as a source of contamination was found to be significant on logistic regression (Figure 1-4). Overall prediction successes of the above model are $88.4 \%$ (sensitivity $53.3 \%$, specificity $96.8 \%$ ).

\section{DISCUSSION}

In Developing countries like ours, peritonitis is one of the causes of the acute abdomen that is associated with high mortality and morbidity.

In this study, appendicitis was the commonest cause of peritonitis, which is consistent with most studies in Ethiopia ${ }^{[2,3,5,6]}$ and Western countries ${ }^{[28]}$. The overall mortality of patients with secondary peritonitis is reported to be between $12 \%$ and $79 \%$ [19, 28-32], while in our study, it is $9.9 \%$. In our study, the incidence of relaparotomy for the postop collection was $23.3 \%$, which is in a higher range than most western literature

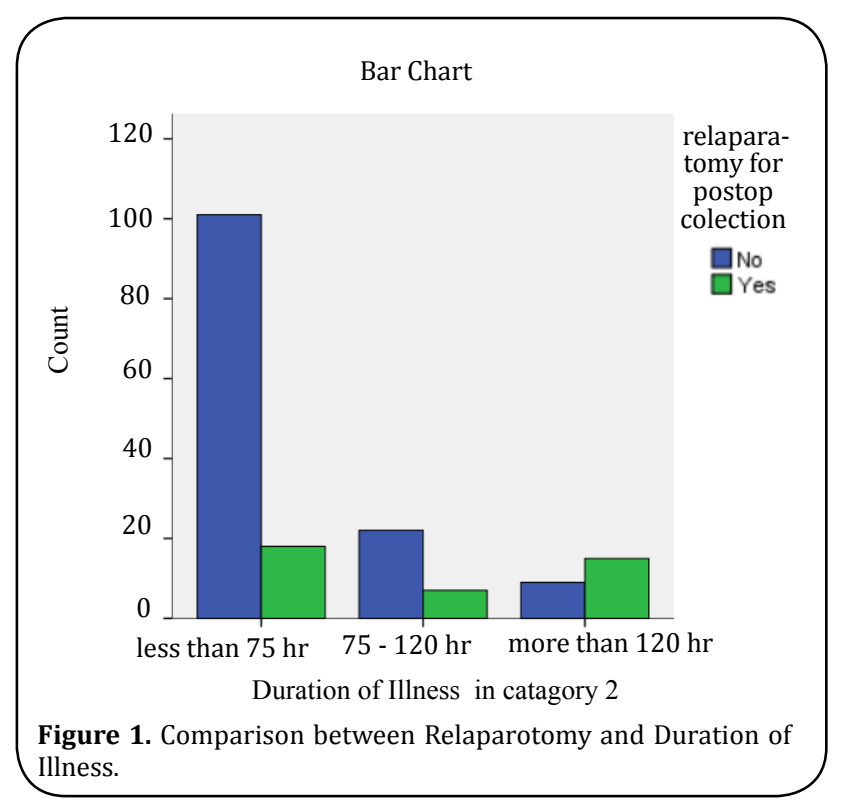

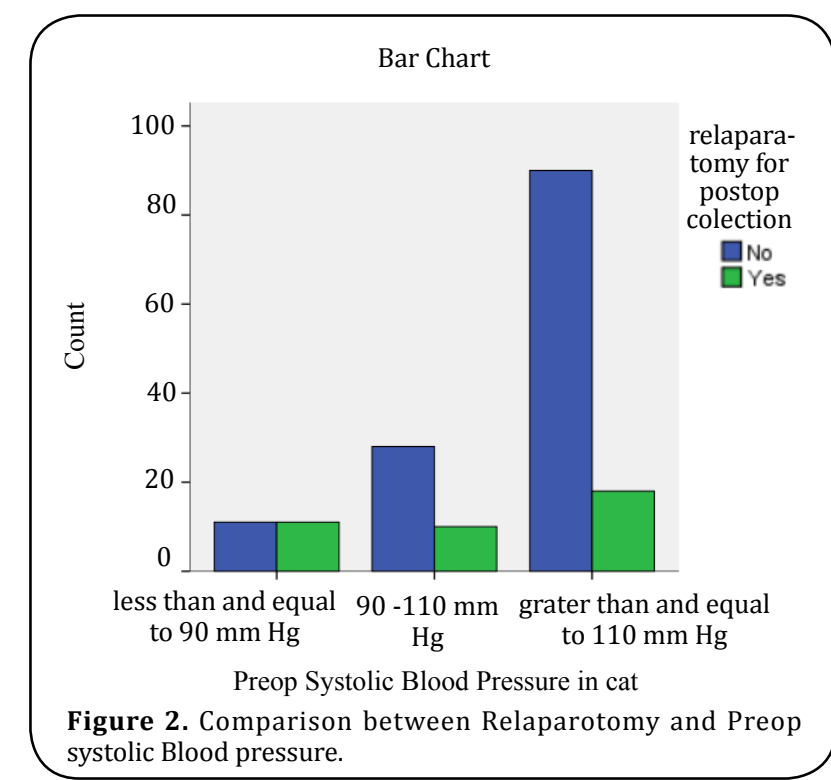
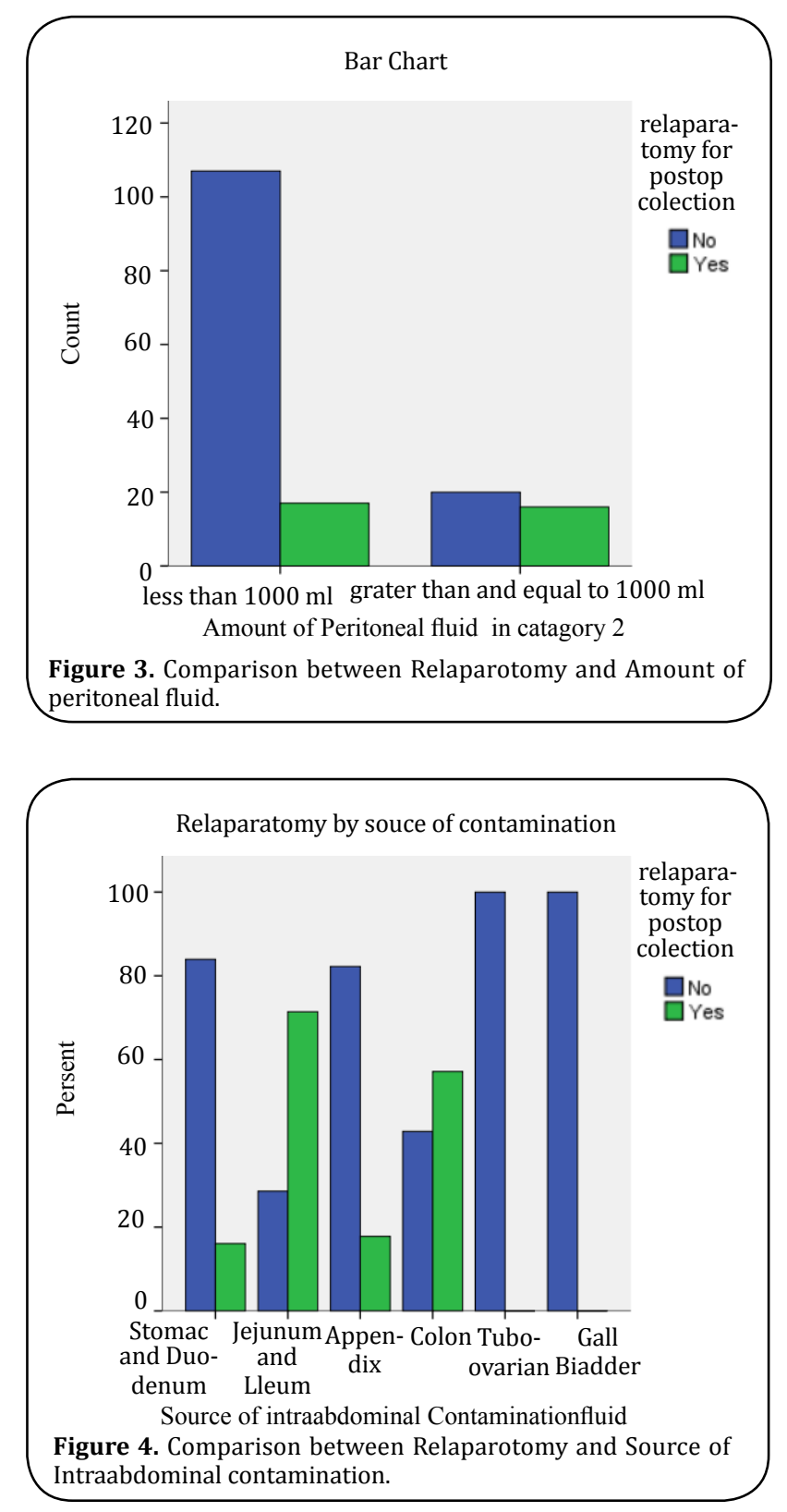
$(0.5-15 \%)^{[11,12]}$. The mortality we observed after relaparotomy was $27.8 \%$, comparable to most studies(24 to $71 \%)^{[12,13,16]}$.

The median interval to relaparotomy was 8 days $(3$ - 58 days) in our studies, which is more than most studies(Hutchins et al. - 5 days) ${ }^{[15]}$. The median duration of hospital stay in our study was 21 days, which was comparable to a Randomized study done in the Netherlands in teaching hospitals (27 days).

We have identified 4 independent predictors of subsequent relaparotomy with multivariate analysis: Duration of illness $>5$ days, Systolic $\mathrm{BP}</=90 \mathrm{mmHg}$, Source of cont. (small bowel) and amount of peritoneal fluid.

A systemic review done by lamme showed age, concomitant disease, upper gastrointestinal source of peritonitis, generalized peritonitis, elimination of the focus, bilirubin, creatinine, lactate, $\mathrm{PaO} 2 / \mathrm{FiO} 2$ ratio, and albumin showed significant association ${ }^{[33]}$.

Another study done in Lithuania by A. Sileikis showed age, CRP, MPI, and duration of surgery as independent predictors for positive relaparotomy ${ }^{[11]}$. In our study duration of surgery showed correlation on univariate analysis, but not in logistic regression. We did not include CRP and MPI b/c retrospective nature of our study.

A study done in Houston, Texas by Jerry J. Kim, showed peripheral vascular disease, alcohol abuse, BMI of 29 $\mathrm{kg} / \mathrm{m} 2$ or higher, the finding of any ischemic bowel at initial laparotomy, and OR latency of 60 hours or longer were good predictors of relaparotomy ${ }^{[34]}$. In our study, we could not include peripheral vascular disease and BMI as variables $b / c$ of the retrospective nature of our study, while the presence of ischemic bowel did not show a correlation.

A South African study done by V Y Kong, on complicated appendicitis found referral from a rural center; duration of illness $>5$ days; heart rate $>120$ bpm; and perforation with associated GC as an independent predictor ${ }^{[35]}$. When comparing to our study, duration of illness was also a strong predictor, while the place of referral had shown correlation on chi-square test, but did not show significant correlation on logistic regression.

From all the above-mentioned studies, we can observe there is no universal model for all; it depends on disease pattern, population distribution, and available resources. As we can see, $45 \%$ of our patients were diagnosed after infectious fluid has leaked through the surgical wound. This signifies signs and symptoms of persistent infection were subtle enough to be missed. So we can use this model to find patients who are at increased risk of post-op collection requiring relaparotomy and intervene early before MODS occurs.

This study has some limitations. The retrospective nature of the study is the main one. A prospective study would have given us a chance to analyze more variables and make a follow-up of patients complete. A smaller sample size makes the generalizability of the study limited. Further prospective validation studies are required before the widespread adoption of this predictive model in clinical practice.

\section{CONCLUSION}

Prevention is the best strategy in the management of persistent intrabdominal infection. The first surgery in peritonitis must be complete to prevent post-op collection. To achieve this, early administration of antibiotics; timely and effective surgical intervention, and Supportive are paramount. Despite the maximum effort, some patients develop a persistent intraabdominal infection. The two main approaches to deal with postop intraabdominal infection are planned and on-demand relaparotomy. Multiple studies have been done to confirm whether planned or on-demand relaparotomy is superior, but still, none of them show significant differences in mortality ${ }^{[28-30,35]}$. These are partly because of a lack of standardized criteria to define when to perform a relaparotomy during disease.

The variables found in our study can be used as one of the criteria to find patients at increased risk of post-op collection, so we can plan a relaparotomy or work up the patients to detect persistent intraabdominal infection before the development of SIRS. This will decrease negative relaparotomy while detecting persistent infection early before the development of MODS. The low sensitivity of the model requires further studies before the widespread use of our predictive model.

\section{DECLARATIONS}

\section{Authors' contributions}

Conceived the project, carried out to acquisition and analysis of data, contributed to drafting and approval of the final manuscript: Abel Shiferaw.

Made substantial contributions to conception and design of the study and provided technical support: Henock T/Selase.

Financial Support and Sponsorship 
Financial support for this article is from Addis Ababa University, College of Health Science. The funding is for covering material costs during the conduction of the study.

\section{Conflict of interest}

The author declares that there is no conflict of interest.

\section{REFERENCES}

1. Farthmann, E. H., \& Schöffel, U. (1990). Principles and limitations of operative management of intraabdominal infections. World Journal of Surgery, 14(2), 210-217.

2. Wossen, M. T., editor Pattern of Emergency Surgical Operations Performed for Non-Traumatic Acute Abdomen at Ayder Referral Hospital, Mekelle University, Tigrai, Ethiopia by the Year 2000-2003 Ec2019. 9(5), 4.

3. Gebrie, T. Management Outcome and Associated Factors of Surgically Treated Non Traumatic Acute Abdomen at Attat Hospital, Gurage Zone, Ethiopia. International Journal of Surgery Research and Practice.

4. Pawulos, W. (2017). Assessment of Non-Traumatic Acute Abdominal Cases Treated Operatively at Wolaita Sodo Teaching and Referral Hospital, Southern Ethiopia. Assessment, 14.

5. Ayenew, Z., Gizaw, A., Workneh, D., \& Fentahun, N. (2016). Outcome of non-traumatic surgical acute abdomen in nekemte referral hospital southwest Ethiopia: a retrospective cross-sectional study. Surgery Current Research, 7(282), 1-5.

6. Berhane, Y., Girmay, K., \& Gebresilassie, A. (2016). Outcome of emergency surgical operations performed for non-traumatic acute abdomen among adults in Mekellehospital. European Journal of Pharmacology Medical Research, 3(14), 106-111.

7. Kujath, P., Rodloff, A. ( 2005). Peritonitis. ed Second edition Bremen, London, Boston, UNIMED, 36-41.

8. Gupta, S., \& Kaushik, R. (2006). Peritonitis - the Eastern experience. World Journal of Emergency Surgery, 1, 13.

9. Malangoni, M. A., \& Inui, T. (2006). Peritonitis - the Western experience. World Journal of Emergency Surgery, 1, 25.

10. Mandell, K., \& Arbabi, S. (2010). Re-laparotomy for severe intra-abdominal infections. Surgical Infections, 11(3), 307-310.

11. Sileikis, A., Kazanavicius, D., Skrebunas, A., Ostapenko, A., \& Strupas, K. (2013). Prediction for a planned relaparotomy in secondary peritonitis.
Central European Journal of Medicine, 8(4), 410414.

12. Unalp, H. R., Kamer, E., Kar, H., Bal, A., Peskersoy, M., \& Onal, M. A. (2006). Urgent abdominal re-explorations. World Journal of Emergency Surgery, 1(1), 1-6.

13. Koirala, R., Mehta, N., Varma, V., Kapoor, S., Kumaran, V., \& Nundy, S. (2015). Urgent Redo-Laparotomies: Patterns and Outcome-A Single Centre Experience. Indian Journal of Surgery, 77(3), 195199.

14. Agalar, F., Eroglu, E., Bulbul, M., Agalar, C., Tarhan, O. R., \& Sari, M. (2005). Staged abdominal repair for treatment of moderate to severe secondary peritonitis. World Journal of Surgery, 29(2), 240-244.

15. Hutchins, R. R., Gunning, M. P., Lucas, D. N., AllenMersh, T. G., \& Soni, N. C. (2004). Relaparotomy for suspected intraperitoneal sepsis after abdominal surgery. World Journal of Surgery, 28(2), 137-141.

16. Krivitskiŭ, D., Shuliarenko, V., \& Babin, I. (1990). Indications for relaparotomy. Klinicheskaia khirurgiia, (1), 18-21.

17. Mayberry, J. C., Goldman, R. K., Mullins, R. J., Brand, D. M., Crass, R. A., \& Trunkey, D. D. (1999). Surveyed opinion of American trauma surgeons on the prevention of the abdominal compartment syndrome. Journal of Trauma and Acute Care Surgery, 47(3), 509-514.

18. Lamme, B., Boermeester, M., Reitsma, J., Mahler, C., Obertop, H., \& Gouma, D. (2002). Meta-analysis of relaparotomy for secondary peritonitis. Journal of British Surgery, 89(12), 1516-1524.

19. Lojpur, B. A., Williams, B. A., \& Sprung, J. (2005). Comparison of on-demand vs planned relaparotomy for treatment of severe intraabdominal infections. Croation Medical Journal, 46(6), 957-963.

20. Lamme, B., Boermeester, M., Belt, E., Van Till, J., Gouma, D., \& Obertop, H. (2004). Mortality and morbidity of planned relaparotomy versus relaparotomy on demand for secondary peritonitis. Journal of British Surgery, 91(8), 1046-1054.

21. van Ruler, O., Mahler, C. W., Boer, K. R., Reuland, E. A., Gooszen, H. G., Opmeer, B. C., ... \& Steller, E. P. (2007). Comparison of on-demand vs planned relaparotomy strategy in patients with severe peritonitis: a randomized trial. Jama, 298(8), 865872.

22. Kong, V. Y., Bulajic, B., Allorto, N. L., Handley, J., \& Clarke, D. L. (2012). Acute appendicitis in a developing country. World Journal of Surgery, 
36(9), 2068-2073.

23. Kong, V., Aldous, C., Handley, J., \& Clarke, D. (2013). The cost effectiveness of early management of acute appendicitis underlies the importance of curative surgical services to a primary healthcare programme. The Annals of The Royal College of Surgeons of England, 95(4), 280-284.

24. Kong, V. Y., Van de Linde, S., Aldous, C., Handley, J. J., \& Clarke, D. L. (2013). Quantifying the disparity in outcome between urban and rural patients with acute appendicitis in South Africa. South African Medical Journal, 103(10), 742-745.

25. Kong, V. Y., Aldous, C., \& Clarke, D. L. (2014). Understanding the reasons for delay to definitive surgical care of patients with acute appendicitis in rural South Africa: general surgery. South African journal of surgery, 52(1), 2-5.

26. Kong, V. Y., Van Der Linde, S., Aldous, C., Handley, J. J., \& Clarke, D. L. (2014). The accuracy of the Alvarado score in predicting acute appendicitis in the black South African population needs to be validated. Canadian Journal of Surgery, 57(4), E121.

27. Clarke, D., Thomson, S., Bissetty, T., Madiba, T., Buccimazza, I., \& Anderson, F. (2007). A single surgical unit's experience with abdominal tuberculosis in the HIV/AIDS era. World Journal of Surgery, 31(5), 1088-1097.

28. Merlino, J. I., Malangoni, M. A., Smith, C. M., \& Lange, R. L. (2001). Prospective randomized trials affect the outcomes of intraabdominal infection. Annals Of Surgery, 233(6), 859.

29. Christou, N. V., Barie, P. S., Dellinger, E. P.,
Waymack, J. P., \& Stone, H. H. (1993). Surgical Infection Society intra-abdominal infection study: prospective evaluation of management techniques and outcome. Archives of Surgery, 128(2), 193199.

30. Koperna, T., \& Schulz, F. (1996). Prognosis and treatment of peritonitis: do we need new scoring systems? Archives of Surgery, 131(2), 180-186.

31. Wittmann, D. H., Schein, M., \& Condon, R. E. (1996). Management of secondary peritonitis. Annals of Surgery, 224(1), 10.

32. Mulier, S., Penninckx, F., Verwaest, C., Filez, L., Aerts, R., Fieuws, S., \& Lauwers, P. (2003). Factors affecting mortality in generalized postoperative peritonitis: multivariate analysis in 96 patients. World Journal of Surgery, 27(4), 379-384.

33. Lamme, B., Mahler, C. W., van Ruler, O., Gouma, D. J., Reitsma, J. B., \& Boermeester, M. A. (2006). Clinical predictors of ongoing infection in secondary peritonitis: systematic review. World Journal of Surgery, 30(12), 2170-2181.

34. Kim, J. J., Liang, M. K., Subramanian, A., Balentine, C. J., Sansgiry, S., \& Awad, S. S. (2011). Predictors of relaparotomy after nontrauma emergency general surgery with initial fascial closure. The American journal of surgery, 202(5), 549-552.

35. Kong, V. Y., van der Linde, S., Aldous, C., Handley, J. J., \& Clarke, D. L. (2014). Developing a clinical model to predict the need for relaparotomy in severe intra-abdominal sepsis secondary to complicated appendicitis. South African journal of surgery, 52(4), 91-95. 